\title{
OUTDOOR EDUCATION CAMP AND GROUP COHESION: AN INVESTIGATION IN THE TEACHER EDUCATION INSTITUTE OF MALAYSIA
}

\author{
M. M. Yasim*, A. Aziz, M. A. Md Taff, and J. Zakaria \\ Faculty of Sports Science and Coaching, Universiti Pendidikan Sultan Idris, Tg Malim, Perak, \\ Malaysia
}

Published online: 10 November 2017

\begin{abstract}
The study seeks to investigate the effect of outdoor education camp toward group cohesion among second year undergraduate teacher trainees from selected Teacher Education Institutes of Malaysia. A pre-test and post-test approach with non-equivalent control group was utilised among 350 second year undergraduate teacher trainees from four selected campuses. A modified version of Group Environment Questionnaire (GEQ) was used to gather data from pre-test and post-test. Results from MANCOVA procedures suggested that the camp had positively improved the group cohesion aspects of the experimental group with significant gain in ATG-T, ATG-S, GI-T and GI-S. Furthermore, results also highlight the improvement of group outcome aspects (GI-T and GI-S) which surpassed individual aspects (ATG-T and ATG-S). Overall, the results of this study showed that outdoor education improves teacher trainees' group cohesion.
\end{abstract}

Keywords: outdoor education; cohesion; teacher; adventure

Author Correspondence, e-mail: mazuki@fsskj.upsi.edu.my

doi: http://dx.doi.org/10.4314/jfas.v9i6s.95 


\section{INTRODUCTION}

Over the last 20 years, outdoor education camps is claimed as powerful medium for learning process for secondary and tertiary educational institutions. Thus many studies have been conducted in examining the effect of outdoor education, especially on personal and social development of participants [1-3]. In general, outdoor education is a form of learning process conducted in both outdoor and indoor settings which encompasses challenging or adventure activities as a medium to foster individual personal and social growth $[4,5]$. According to Foley [4], outdoor education is a broad field of studies and often referred to as adventure education, adventure programming, outdoor learning, outdoor school, adventure therapy, adventure recreation, adventure tourism, expeditionary learning, challenge education, experiential education, environmental education, and wilderness education.

Outdoor education has been proven useful in promoting academic achievement, work commitment, critical thinking, and in preventing delinquency [6, 7]. Typically, the stated objectives of outdoor education are to improve group cohesion, leadership skills, improving problem-solving skills, self-conceptualization, increasing trust, and improving communication $[1,8,9]$. In other words, the emphasis on interpersonal and intrapersonal relationships is frequently considered to be the primary highlight of outdoor education researcher [Priest \& Gass, 10, 11].

Generally, outdoor education involves adventure activities that is planned and designed with the use of environment, nature and encourages sharing experience as a medium of teaching and learning process. The importance of knowledge and experience sharing in the process of learning has been acknowledged by world renown theorists such as Lewin, Dewey and Piaget [12]. The engagement of experiential sharing process among participants will allow them to create relationships and practice a new identity in a safe and supportive environment [13]. According to Kolb [14], experiential sharing is an integral part of learning in outdoor education programs. He emphasizes experiential learning as a process of building knowledge through experience. Based on Kolb's model, it refers to the experience as a virtuous circle, where participants start and finish with a concrete experience. These experiences can take shape in many forms like an element in outdoor education camp. 
In Malaysia, outdoor education has been developed as a consequence of Razak Report 1956 (the first education report) which stressed on national unity through the education system. This report was crucial to educational development in Malaysia as it led towards the establishment of The National Education Policy (NEP) in 1961. The primary objective of NEP is to achieve national unity and development through education [15] has become a tool of social rejuvenation system in Malaysia [16]. As a result, the Ministry of Education has drafted the Malaysian education system that focuses on the development of physical, emotional, spiritual and social well-balanced individual as stipulated in the NEP [17]. In achieving these goals, the Teacher Education Division (TED) had to play an integral role in the establishment of excellent teachers in schools all over Malaysia.

Teacher quality is a fundamental characteristic towards the success of NEP. With regard to the goal, TED has set the philosophy of teacher education which outlines:

"Teacher, who is noble in character, progressive and scientific in outlook, committed to uphold the aspirations of the nation, and cherishes the national cultural heritage, ensures the development of the individual and the preservation of a united, democratic, progressive and disciplined society" [18].

Hence, TED has prepared the curriculum and syllabus based on the philosophy outlined which equally balanced the: (1) academic, (2) co-curricular, and (3) internship aspect of teacher education [19]. One of the academic component of teacher education in Malaysia enlists outdoor education subject as a medium for students' psychosocial development, hard skill and management skill [20]. This subject incorporates academic learning and active participation outdoor education practical which includes camping programmes in remote area. The main focus of the programme is to gain personal and social development [21-23]. The subject is divided into three parts; (1) weekly theoretical class, (2) weekly practical session and (3) participation in outdoor education camping. Outdoor education camping in the Teacher Education Institutes of Malaysia is normally conducted in remote setting such as the mountain region or islands. The outcome of the programme is expected to increase students' personal and social development, management skill, and outdoor pursuit skills. 
Normally, weekly theoretical class covers outdoor education topics, such as philosophy, history, leadership, management strategies and current issues in outdoor education. Meanwhile, weekly practical class exposes students to various outdoor pursuit skills ranging from basic camping skill to land and water based adventure activities such as kayaking, orienteering, abseiling, survival and trekking. By the end of the semester, the teacher trainees will have participated a six-days in outdoor education camping. Traditional base camp approach is used where the students sleep in tents and prepare their own meals. During the camp, the students will participate in several outdoor pursuit expeditions such as kayaking, trekking, boating, orienteering and abseiling which are done on a daily rotation basis. At night, they will be geared for a series of group discussions, games and group presentations. These activities are conducted to reinforce their outdoor education camp learning experience. This camping programme emphasized positive affective values and promotes behavioural change especially group cohesion with adventure activities as a medium of learning.

To date, many outdoor educators and researchers have proposed that participation in outdoor education camps is effective in fostering participants' group cohesion [24-32]. This assumption was made as outdoor education emphasized on the importance of interpersonal relationship and group cohesion [33]. However, the effectiveness of outdoor education camps as a catalyst for the formation of group cohesion is debatable, due to inconsistent findings. For instance, several studies in outdoor education camps found insignificant results of group cohesion enrichment, and inconsistent finding on task and social aspects that influences group cohesion [34]. While others reported participants did not show any changes after experiencing learning in environmental setting due to lack of classroom reinforcements $[35,36]$, less effects on behavioural outcomes, lack of appropriate sequence of activities and insufficient transfer of learning.

These inconsistent findings posed a challenge to the implementation of outdoor education in Malaysian educational system, especially the socio-economic aspects of the subject. As camping involves abundant time of planning, resources and finances, the current scenario of inconclusive effects of camping is tapping outdoor education subject at stake. Therefore, amidst these inconclusive findings, there is a need for a systematic research to gather empirical evidence in order to support the claims that outdoor education camp in the Teacher 
Education Institutes of Malaysia have a positive impacts on group cohesion [38]. Specifically, the current study posed a critical question to the implementation of outdoor education camps in Teacher Education Institute of Malaysia about impact of outdoor education camp on students' group cohesion. Finding from this research will underline the future body of knowledge, curriculum and practices of outdoor education camp on group cohesion in Teacher Education Institute of Malaysia.

\section{METHODOLOGY}

\subsection{Sample}

The current study involved intact group following a quasi-experimental design (none randomized) with utilised a pre-test and post-test with control group [39]. A pre-test and post-test design allowed us to compare these conditions in both immediate learning gains (at the end of instruction) [40]. The population of this research comprised of 350 second year undergraduate students (aged between 18-25 years old) form selected Teacher Education Institutes of Malaysia who major in Physical Education and Health studies were appointed as experimental group $(n=178)$ while second year Social Studies students were selected as control group $(\mathrm{n}=172)$. The experimental group is required to undergo outdoor education camp for six day and five nights meanwhile the control group did not participate in any outdoor education camp but were administered with pre-test and post-test at their respective campuses.

\subsection{Instrument}

A modified version of Group Environmental Questionnaire (GEQ) [41] was employed to both groups in which the experimental groups participated in outdoor education camp organised by the respective campus. Meanwhile, control group did not receive any treatment at all. The questionnaire was used to measure the impact of outdoor education camp on students' group cohesion. The GEQ has 18 items presented on a 9-point scale anchored at the extremes by strongly agree (9) to strongly disagree (1). Scoring was treated as interval data which consists of four dimension constructs namely Group Integration-Task (GI-T), Group 
Integration-Social (GI-S), Individual Attraction to the Group-Task (ATG-T), and Individual Attraction to the Group-Social (ATG-S) [42].

\subsection{Procedure}

The GEQ was administered through the pre and post-test for both the experimental and control group. In the pre-test, both groups were tested on the same day at their respective campuses before the experimental group leave for their outdoor education camp. Then, once the experimental group completed their treatment (outdoor education camp) which lasted for six days and five nights, both groups were given the post-test at their respective campus.

\begin{tabular}{|c|c|}
\hline \multicolumn{2}{|r|}{$\begin{array}{c}\text { Control Group } \\
\text { Non Equivalent group without } \\
\text { treatment }\end{array}$} \\
\hline $\begin{array}{c}\text { Perlis Campus ( } n=45 \text { ) } \\
\text { Physical Education studies }\end{array}$ & $\begin{array}{l}\text { Perlis Campus ( } n=43 \text { ) } \\
\text { Social studies }\end{array}$ \\
\hline $\begin{array}{l}\text { Raja Melewar Campus ( } n=43 \text { ) } \\
\text { Physical Education studies }\end{array}$ & $\begin{array}{l}\text { Raja Melewar Campus ( } n=43 \text { ) } \\
\text { Social Studies }\end{array}$ \\
\hline $\begin{array}{l}\text { Tun Abdul Razak Campus }(n=44) \\
\text { Physical Education studies }\end{array}$ & $\begin{array}{l}\text { Tun Abdul Razak Campus }(n=44) \\
\text { Social Studies }\end{array}$ \\
\hline $\begin{array}{l}\text { Temenggung Ibrahim Campus }(n=46) \\
\text { Physical Education studies }\end{array}$ & $\begin{array}{l}\text { Temenggung Ibrahim Campus }(n=42) \\
\text { Social Studies }\end{array}$ \\
\hline \multicolumn{2}{|c|}{ Post-Test } \\
\hline
\end{tabular}

Fig.1. Design of the Study

\section{RESULT}

Data of the study was collected from 350 students $(\mathrm{N}=350)$ from four different campuses which then were divided into two groups: (1) experimental group $(n=178)$, which involved teacher trainees who participated in outdoor education camps and and (2) control group $(n=172)$, comprised of those who have not participated in any outdoor education camp.

The MANOVA and MANCOVA analysis was conducted to see the comparison between the control and experimental groups before and after the treatment. 
Table 1. Result of the MANOVA Examining the Level of Group Cohesion before the Camp

\begin{tabular}{|c|c|c|c|c|}
\hline Effect & $\begin{array}{c}\text { Multivariate } \\
\text { Analysis }\end{array}$ & $\mathbf{F}$ & $\mathbf{P}$ & $\begin{array}{c}\text { Partial Eta } \\
\text { Square }\end{array}$ \\
\hline Intercept & Wilks' Lambda & $4461.181^{\mathrm{b}}$ & $.001 * *$ & .981 \\
\hline Group & Wilks' Lambda & $6.880^{\mathrm{b}}$ & $.001 * *$ & .074 \\
\hline
\end{tabular}

Design: Intercept + Group ${ }^{*} \mathrm{p}<0.05 * * \mathrm{p}<0.01$

b. Exact statistic

Table 2. Results of Univariate ANOVA Examining the Level of Group Cohesion before the Camp

\begin{tabular}{ccccccccc}
\hline $\begin{array}{c}\text { Dependent } \\
\text { Variable }\end{array}$ & $\begin{array}{c}\text { Experimental } \\
(\mathbf{n = 1 7 8})\end{array}$ & \multicolumn{2}{c}{$\begin{array}{c}\text { Control } \\
(\mathbf{n = 1 7 2})\end{array}$} & & \multicolumn{2}{c}{ Univariate ANOVA } \\
\hline Pre GEQ & $\square$ & $\mathrm{Sd}$ & $\square$ & $\mathrm{Sd}$ & $\mathrm{F}$ & $\mathrm{p}$ & $\begin{array}{c}\text { Partial Eta } \\
\text { Squared }\end{array}$ \\
Pre ATG-T & 26.48 & 5.607 & 26.8 & 5.75 & 4.681 & $0.031^{*}$ & 0.013 \\
Pre ATG-S & 33.42 & 5.216 & 34.1 & 5.209 & 23.229 & $0.001 * *$ & 0.063 \\
Pre GI-T & 32.55 & 5.463 & 33.34 & 6.608 & 1.478 & 0.225 & 0.004 \\
Pre GI-S & 25.07 & 4.514 & 25.12 & 6.251 & 0.006 & 0.941 & 0.001 \\
\hline${ }^{*} \mathrm{p}<0.05$ & $* * \mathrm{p}<0.01$ & & & & & & &
\end{tabular}

The above Table 1, MANOVA analysis revealed that the subscales of the GEQ significantly affected the group. Using an alpha level of .05, it revealed that this test is significant (Wilks' $\Lambda=.926, F(1,348)=6.880, p=0.001, \eta 2=0.074)$. The multivariate $\eta 2=0.074$ indicated that $7.4 \%$ of multivariate variance of the dependant variable is associated with the group factor. The multivariate effect sizes were medium $[43,44]$.

Significant effects in the MANOVA analysis (Table 1) were further investigated with Univariate ANOVA (Table 2). Table 2, ANOVA results revealed that both experimental and control group showed significant differences for the subscale of ATG-T $(F(1,348)=4.681$, $p=.031, \eta 2=.013)$ and ATG-S $(F(1,348)=23.229, p=.001, \eta 2=.063)$. Meanwhile, no significant differences were found between experimental and control groups for the GI-T ( $F$ $(1,348)=1.478, p=.225, \eta 2=.0 .004)$ and GI-S subscale $(F(1,348)=0.006, p=.941, \eta 2=$. 0.001). The analysis revealed that multivariate effect sizes were found low and very small effect sizes for most subscales. Overall, there was no significant difference for the pre-test 
mean scores between groups in the ATG-T and ATG-S. However, the analysis revealed significant differences on the GI-T and GI-S subscales before the camp.

Table 3. Results of the MANCOVA Test Examining the Level of Group Cohesion after the

\begin{tabular}{|c|c|c|c|c|}
\hline \multicolumn{5}{|c|}{ Camp } \\
\hline Effect & $\begin{array}{c}\text { Multivariate } \\
\text { Analysis }\end{array}$ & $\mathbf{F}$ & $\mathbf{P}$ & $\begin{array}{c}\text { Partial Eta } \\
\text { Square }\end{array}$ \\
\hline Intercept & Wilks' Lambda & $34.410^{b}$ & $.001 * *$ & 0.288 \\
\hline Group & Wilks' Lambda & $9.474^{b}$ & $.001 * *$ & 0.1 \\
\hline Pre ATG-T & Wilks' Lambda & $2.428^{b}$ & $.048^{*}$ & 0.028 \\
\hline Pre ATG-S & Wilks' Lambda & $6.736^{b}$ & $.001 * *$ & 0.079 \\
\hline Pre GI-T & Wilks' Lambda & $4.221^{\mathrm{b}}$ & $.002 *$ & 0.047 \\
\hline Pre GI-S & Wilks' Lambda & $7.752^{b}$ & $.001 * *$ & 0.083 \\
\hline
\end{tabular}

a. Design: Intercept + pre ATGS + pre ATGT + pre GIT + pre GIS + Group

b. Exact statistic

$* \mathrm{p}<0.05 \quad * * \mathrm{p}<0.01$

Table 4. Results of Univariate ANOVA Examining the Level of Group Cohesion after the Camp

\begin{tabular}{|c|c|c|c|c|c|c|c|}
\hline \multirow[t]{2}{*}{$\begin{array}{c}\text { Dependent } \\
\text { Variable }\end{array}$} & \multicolumn{2}{|c|}{$\begin{array}{l}\text { Experimental } \\
\qquad(n=178)\end{array}$} & \multicolumn{2}{|c|}{$\begin{array}{l}\text { Control } \\
(n=172)\end{array}$} & \multicolumn{3}{|c|}{ Univariate ANOVA } \\
\hline & $\square$ & Sd & $\square$ & Sd & $\mathbf{F}$ & $\mathbf{p}$ & $\begin{array}{c}\text { Partial Eta } \\
\text { Squared }\end{array}$ \\
\hline \multicolumn{8}{|l|}{ Post GEQ } \\
\hline Post ATG-T & 28.46 & 5.85 & 26.74 & 5.667 & 10.828 & $.001 * *$ & 0.031 \\
\hline Post ATG-S & 34.76 & 6.635 & 34.05 & 6.2 & 4.149 & $.042 *$ & 0.012 \\
\hline Post GI-T & 35.72 & 6.167 & 33.62 & 6.563 & 14.899 & $.001 * *$ & 0.042 \\
\hline Post GI-S & 28.53 & 4.493 & 25.17 & 6.339 & 34.274 & $.001 * *$ & 0.091 \\
\hline Covariate & DV & & & & & & \\
\hline \multirow[t]{4}{*}{ Pre ATG-T } & \multicolumn{2}{|c|}{ Post ATG-T } & & & 9.17 & $.008 *$ & 0.065 \\
\hline & \multicolumn{2}{|c|}{ Post ATG-S } & & & 0.184 & 0.668 & 0.001 \\
\hline & \multicolumn{2}{|c|}{ Post GI-T } & & & 0.411 & 0.522 & 0.001 \\
\hline & \multicolumn{2}{|l|}{ Post GI-S } & & & 0.193 & 0.661 & 0.001 \\
\hline Pre ATG-S & \multicolumn{2}{|c|}{ Post ATG-T } & & & 2.056 & 0.153 & 0.006 \\
\hline
\end{tabular}




\begin{tabular}{rlrrc}
\hline & Post ATG-S & 8.771 & $.033^{*}$ & 0.025 \\
& Post GI-T & 1.4 & 0.238 & 0.004 \\
& Post GI-S & 0.048 & 0.826 & 0 \\
\multirow{3}{*}{ Pre GI-T } & Post ATG-T & 0.791 & 0.374 & 0.002 \\
& Post ATG-S & 3.546 & 0.061 & 0.01 \\
& Post GI-S & 0.705 & 0.36 & 0.004 \\
& Post GI-T & 25.728 & $.001 * *$ & 0.07 \\
& Post ATG-T & 0.68 & 0.41 & 0.002 \\
& Post ATG-S & 0.027 & 0.869 & 0 \\
& Post GI-S & 14.799 & $.001 * *$ & 0.041 \\
& Post GI-T & 2.879 & 0.098 & 0.008 \\
\hline
\end{tabular}

Meanwhile, after the camp a one-way MANCOVA (Table 3) was conducted to examine the effect of group on all four subscales (ATG-T, ATG-S, GI-T and GI-S) while controlling the pre-test scores. The data revealed that the groups (experimental and control) showed significant effect on the post-test subscales score (Wilks' $\Lambda=.900, F(1,344)=9.474, p=$ $0.001, \eta 2=0.1)$. Meanwhile, the covariates of pre ATG-T scores (Wilks' $\Lambda=.972, F(1,344)=$ 2.428, $p=0.048, \eta 2=0.028$ ), pre ATG-S scores (Wilks' $\Lambda=.981, F(1,344)=6.736, p=$ $0.001, \eta 2=0.079)$, pre GI-T scores (Wilks' $\Lambda=.917, F(1,344)=4.221, p=0.002, \eta 2=0.047)$ and pre GI-S scores (Wilks' $\Lambda=.953, F(1,344)=7.752, p=.001, \eta 2=.083$ ). Overall, it was found that, all covariates significantly influenced the post subscales scores.

However, Univariate ANOVA (Table 4) discovered that the experimental group's post ATG-T subscale score significantly differ from the control group $(F(1,344)=10.828, \mathrm{p}=$ $.001, \eta 2=.031$ and the covariate of pre ATG-T test $(F(1,344)=9.17, p=0.008, \eta 2=0.065)$. Meanwhile, for post ATG-S subscale, result shows experimental group score is significantly higher from the control group $(F(1,344)=4.149, \mathrm{p}=.042, \eta 2=0.012)$ and the covariate of pre ATG-S test $(\mathrm{F}(1,344)=8.771, \mathrm{p}=0.033, \eta 2=0.025)$.

A similar result was recorded in post GI-T subscale score as the experimental group score differs significantly than the control group $(F(1,344)=14.899, \mathrm{p}=.001, \eta 2=0.042)$ and the covariate of pre GI-T test $(F(1,344)=25.728, p=0.001, \eta 2=0.07)$. Lastly, the experimental group scored significantly higher in the post GI-S subscale than control group $(F(1,344)=$ 
$34.274, \mathrm{p}=.001)$ and the covariate of pre GI-S test $(F(1,344)=3.931, p=0.001, \eta 2=0.044)$ significantly influence the post test results. The experimental group scored higher than the control group in all subscales with mean comparison of post-test scores revealed that the experimental group had significantly higher group cohesion than the control group after the outdoor education camp.

\begin{tabular}{cccccccc}
\hline $\begin{array}{c}\text { Dependent } \\
\text { Variable }\end{array}$ & \multicolumn{2}{c}{$\begin{array}{c}\text { Experimental } \\
(\mathbf{n = 1 7 8})\end{array}$} & \multicolumn{2}{c}{$\begin{array}{c}\text { Control } \\
(\mathbf{n = 1 7 2})\end{array}$} & \multicolumn{2}{c}{ Univariate ANOVA } \\
\hline Pre GEQ & $\square$ & $\mathrm{Sd}$ & $\square$ & $\mathrm{Sd}$ & $\mathrm{F}$ & $\mathrm{p}$ & $\begin{array}{c}\text { Partial Eta } \\
\text { Squared }\end{array}$ \\
Pre ATG-T & 26.48 & 5.607 & 26.8 & 5.75 & 4.681 & $0.031^{*}$ & 0.013 \\
Pre ATG-S & 33.42 & 5.216 & 34.1 & 5.209 & 23.229 & $0.001^{* *}$ & 0.063 \\
Pre GI-T & 32.55 & 5.463 & 33.34 & 6.608 & 1.478 & 0.225 & 0.004 \\
Pre GI-S & 25.07 & 4.514 & 25.12 & 6.251 & 0.006 & 0.941 & 0.001 \\
\hline
\end{tabular}

$* \mathrm{p}<0.05 \quad * * \mathrm{p}<0.01$

\section{DISCUSSION}

\subsection{Level of GEQ before the Camp}

During pre-test, both groups showed a favourable degree of group cohesion with the score of experimental group for pre GI-T $(\mathrm{M}=32.55, \mathrm{SD}=5.463)$ and pre GI-S $(\mathrm{M}=25.07, \mathrm{SD}=4.514)$ showed no significant difference with the score of control group for pre GI-T $(M=33.34$, $\mathrm{SD}=6.608)$ and pre GI-S $(\mathrm{M}=25.12, \mathrm{SD}=6.251)$ subscales. However, significant differences were found between experimental and control group which the finding revealed that experimental group scored lower for pre ATG-T $(\mathrm{M}=26.48, \mathrm{SD}=5.607)$ and pre ATG-S $(\mathrm{M}=33.42, \mathrm{SD}=5.216)$ as compared to control group scored higher for pre ATG-T $(\mathrm{M}=26.8$, $\mathrm{SD}=5.75)$ and pre ATG-S (M=34.1, $\mathrm{SD}=5.209)$ subscales.

These scores explained about the personal involvement of an individual pertaining to the group's goals and objectives associated with the task and social aspect before the camp. Both groups scored above midpoint of the scale and considered as having positive perception toward group cohesion (mean score for both groups more than 25). In overall, the control group scored slightly higher than the experimental group for all subscales in the pre-test. The 
higher score represented greater sense of connectedness to the group. Thus, the researcher proposed several potential reasons for these findings.

Firstly, the control group was selected from Social Studies programme which are formally exposed to the importance of diversity and respect towards others [45]. Their Social Studies experiences is believed to promotes a sense of belonging and acceptance as they engage actively in several socio-activities at the local, community, provincial, national and global level [46]. As a result, they recorded significantly positive in their group cohesion scores. Meanwhile, personal and social value is not taught directly but embedded in several subjects of Physical Education studies [47]. Therefore, the researcher proposed that the difference in academic approach between Social Studies and Physical Education field of studies may have influenced group cohesion scores between the groups.

Secondly, the researcher also presumes that the difference of scores was mediated by the prior social experience that students gain in their respective campus before the camp. Since both groups were in the third semester, the social experience factor might influence their perception toward group cohesion. The possibility is supported by Gurin, Dey, Hurtado, and Gurin [48] which explained that peer diversity and structural features of campus like size, percentage of students, rules, and peer group has indirect influence on students' social cohesion.

Thirdly, the influence of previous experience in outdoor recreation or co-curriculum programme is believed to inspire their perception toward group cohesion. Based on the demographic data, it was showed that more than $50 \%$ of the respondents from both groups had previous experience in outdoor recreation in various outdoor recreation programmes. Most of literatures would suggest that there exist positive relationship with what individual do previously in their lives with what they interpreted or do later [49]. Lewis [50] addressed that previous outdoor experiences are important factor that can influence the development of positive group cohesion in outdoor education.

Lastly, the researcher presumes that this might be caused by the influence of students' gender. To support, based on the descriptive analyses on students gender between groups, it was found that the experimental group comprised of 53.4 percent (95) male and 46.6 percent (83) female students. Meanwhile, the control group consisted of 31.4 percent (54) males and 68.6 
percent (118) females students. A further analysis was conducted and the researcher found that female respondents in the both group scored greater than male respondents.

The influence of gender in the present study was in line with Digby's [51] review of gender differences in outdoor education attitudes and behaviours. They found that women were having stronger group cohesion than men. It was assumed that female have been found to be more comfortable in group process where feelings are being shared whereas males are more comfortable in groups focused on tasks [52]. This probably because of their role in childbearing and child rearing, women are believed to be closer to nature [53].

On the other hand, the pre-test findings also revealed that among the four subscales of GEQ, the ATG-T and ATG-S subscales were having significant differences between the groups. As control scored significantly higher than experimental groups in both subscale, the researcher assumed that personal and individual perceptions might have an influence on this finding. Carron et al.,[54] highlights that the individual attractions subscales (ATG-T and ATG-S) required a students' judgment which is more toward personal and individual perception. Individual attractions to the group relates to the student's beliefs about what attracted them to the team [55]. This can be seen on each items on both subscales which requiring "I," "my," and "me" assessments that encourage students to focus within themselves and ignore the experiences of other group members. Therefore, the items in both subscales contain personal perception perhaps encourage students to focus outside themselves and consider common experiences as a reference and thus make different view on group cohesion before the camp [54]. The above claims were strong evidences for the insignificant differences in the ATG-T and ATG-S subscales score for both groups.

The current finding similar to Tazein and Meshkati, [56] who studied group cohesion among volleyball, basketball and handball games. They found that there were significant differences of the ATG-T and ATG-S subscales in the pre-test scores between control and experimental group. They highlights that this difference was due to the various aspects of their character upon group cohesion. To further relate the claim, Whitaker [57] explained one of the early stages of group development is inclusion, where new members are anxious with how to become a part of the team. It is influenced by the cohesive interaction which is characterized by group members sharing information with one another about their lives outside of the group 
[58]. Interestingly, since both groups are a new group, the researcher theorized that they are in the process of inclusion stage where judgment is more on personal and individual. Therefore, there were differences of their perception for both groups toward ATG-T and ATG-S subscales.

On the other hand, the current finding also revealed that there is no statistically a difference between the experimental and control groups' score for the GI-T and GI-S subscales. The researcher presumes that perceptions of both groups were generally equivalent in group nature for the GI-T and GI-S subscales at the beginning of the research. This is affirmed by Dion [59], which outlined that perceptions of cohesion between groups tend to similar when they not differ in group nature. Study conducted by Zaccaro, Blair, Peterson, and Zazanis [60] have pointed out that the social nature of the group influences how individual's perceptions develop. This is consistent with Boyle's [26], view about group in his research. Boyle which studied group cohesion in adventure education posited that, when people get together they are more positive about group.

Furthermore, the group integration subscales (GI-T and GI-S) of the GEQ demand individual judgment about general state of the group. Therefore, the items in both subscales contain statement "we," "us," and "the group" assessments perhaps encourage students to focus outside themselves and consider common experiences as a reference and thus make similar view on group cohesion before the camp [54]. The above claims were strong evidences for the insignificant differences in the GI-T and GI-S subscales score for both groups.

From the view of task and social aspects, it was found that both groups scored slightly higher in the ATG-S (social) and GI-T (task) subscales with the experimental group scored M=33.42 for the ATG-S and M=32.55 for the GI-T subscales. Meanwhile the control group scored $\mathrm{M}=34.1$ for the ATG-S and M=33.34 for the GI-T. The findings looks contradict to the literature which addressed the task-related aspects (ATG-T and GI-T) of cohesiveness are more likely to characterize a team's cohesiveness than the social aspects (ATG-S and GI-S) of cohesiveness at early stage of group's development [61]. These mixed finding differs from previous research which consistently found the ATG-T or task aspect to be a predictor of objective measures of group productivity [e.g 27, 62, 63, 64]. 
This different pattern of finding could be due to the nature of both groups in this study. As mentioned earlier, both groups were in the third semester and enrolled for Hubungan Etnik (Ethnic Relations) subject. At the same time, the experimental group from Physical Education programme enrolled for the outdoor education subject as treatment which the subject was purposely designed for socially oriented activities and focus more on the personal and social growth [65]. On the other hand, the control group from Social Studies field also in the third semester but had no treatment (outdoor education camp) given. However, as both groups experienced social relationship in their informal activities and daily life before the pre-test, it probably has influenced their perception about the group. Carron, Widmeyer, and Brawley [66] asserted that social cohesion refers to activities associated with developing and maintaining harmonious social relationships. Informal activities outside of the programme, such as eating meals in group, recreational activities, social functions, and even practical jokes that are in the spirit of fun, are important considerations in developing social relationship, social support, and personal bonding [67]. The high score for the GI-T scales before the camp may reflect the fact that group give high emphasis on group-related planning and interactions during preparation as they prepare for the daily task and upcoming camp.

\subsection{Level of GEQ after the Camp}

After the camp, the results indicate that the experimental group recorded statistically higher group cohesion scores than the control group. A huge score improvement occurred in the experimental group. This finding support the claims that group which exposed to outdoor education camp treatment would increase scores on all the GEQ subscales [68]. Based on the task and social aspects, the experimental group scored by more than three points on the perceptions of the group as a total unit working toward social aspects of team cohesion (GI-S) and as well as the perceptions of the group as a total unit working toward task aspects of team cohesion (GI-T) subscales after the camp.

Whereas the individual attraction to the group to execute task aspects (ATG-T) and the individual attraction to the group to execute social aspects (ATG-S) only increased by almost two points. It is important to note that, individual factors of cohesion are not always noted in 
the research but cohesion in general is linked to success between work groups, so guiding the research to determine which factors of cohesion have the strongest effect may be useful [69]. The higher score of the GI-S and GI-T indicated that majority of the respondents feeling more comfortable and cohesive at the group level than individual level. Social and task aspects scored in the GI-S and GI-T reflect a high degree of groupness, which predicted the group variance in perceptions of group satisfaction [61]. The researcher presumes that the lower score of individual level of task and social related aspect maybe because of the nature of the programme.

As discussed earlier, the outdoor education programme is designed to promote group cohesion which focuses more on the group process to accomplish the outdoor pursuit activities but not much on task aspect [12]. Therefore, individual group member perceptions' of group condition is one of the vital links between group process and outcome [30]. Members of groups who feel that they have a great group condition will have more positive outcomes than groups whose members feel like there is a negative group climate.

Overall, the results of this study suggest that outdoor education programme can obtain notable and particularly strong outcomes regarding group cohesion. The researcher proposed several possible reasons for these findings. Firstly, the researcher believed that the outdoor education camps itself contributes to the improvement of group cohesion of the experimental groups. The camping programme that was conducted in four different locations in six days that away from their normal daily routine has played an important role for the changes. This is supported by Priest and Gass [10] and Wilding [70] which claimed that a new and novel setting which is away from the familiarity of "normal" daily routines or "comfort zone" was documented as one of the antecedents for change in an adventure-based programming setting. The researcher believes that the increase that occurred in this study is likely to be caused by factors which the students were not subject to interference from outside and negative influences. Since it was conducted away from normal daily routine, with traditional camping method and used less technological devices, students have more time to bring the group closer together as a social group and increase view toward group cohesion [71]. This is supported by Milton and Cleveland [72] which states that the individual that is placed in a quiet and stress-free experience and capabilities of the new attractions to tend to be more cohesive. 
While in the camp, they are free to talk, discuss, sleep together in a tent, exercise, eat together, trust, share responsibility, touch each other, seek for help and work as a team to accomplish shared objectives and tasks. Particularly, the researcher's claims were coherent to the studies conducted by Glass and Dotson-Blake [73] and Wilding [70].

These researchers found that all form of togetherness and adventurous experiences in order to accomplish physically and mentally demanding tasks give students and members of their group a chance to realize they are not alone in their struggles and thus socially bond the group $[70,73]$. Element of togetherness was shared and applied in the whole camp members when they need to collaborate in order to accomplish the task [74]. Therefore, these activities exert a great influence of the improvement of group cohesion among students.

Secondly, a further investigation on instructional plan for outdoor education subject prepared by Ministry of Education for the Teacher Education Institute of Malaysia found that, group cohesion was highlighted as one of the main concern objectives. Through this objective, the programme was designed and implemented during the camps with the entire programme was conducted in a natural environment. As a consequence, all of the outdoor pursuit activities selected was designed with group cohesion as one the priority values such as camping, kayaking, orienteering, camp craft, survival, and others. During these activities, they are encouraged to participate and cooperate which requires high degree of interpersonal relationship in a way that promotes group cohesion. Then, at the end of the each session, it was reinforced by the debriefing session which led by a lecturer to discuss and reflect about what they have gained from the activities.

Breunig et al., [75] and Yuen, Pedlar, and Mannell [76], had long highlighted about the influence of the above variables. They proposed that an appropriate debriefing of experiences, activities, unfamiliar environment and sense of getting away was discovered as influenced and encouraged group cohesion through outdoor education camping. The use of natural environment that places physical and emotional demands reliance on others in the group [77]. The researcher's claim regarding these issues was supported by several previous local and international studies $[26,31,78]$.

Finally, the researcher assumed that a comprehensive understanding of the notion of Kolb's (1984) Experiential Learning Model enhanced students' learning experiences that maybe 
transformed towards their group cohesion potential. Through researcher's observation, it was found that students improved teamwork skills. While they were in the outdoor education camp, each member in groups take advantage of their strengths, respect group members, communicate effectively with team members to resolve conflict and used various method to deliver a messages. The notion of the above models has been used to refer to everything from kinaesthetic, directed instructional activities in the classroom to special workplace projects interspersed with serious discussion led by a lecturer to learning generated through social action movements, and even to team-building adventures in the wilderness [79].

Therefore, the researcher believed that the application and understanding of the Experiential Learning Model have greatly influenced students' experiences and the way they learnt. The researcher presumes that these theoretical frameworks which act as a basis may instil and increase positive student's interpersonal and thus applicable in gaining their group cohesion. The theory has been proven effective in improving personal and social development and has close relationship with outdoor education field.

In contrast, the control group was not exposed to any outdoor education camp intervention. Thus, their source of group cohesion information probably limited to their Hubungan Etnik (Ethnic Relations) subject, social studies field, personal activities and previous knowledge without much hands on approach. Analyses from the MANCOVA on post-test scores suggested that the score obtained by the control group on group cohesion is almost stagnant between pre-test and post-tests. According to this finding, the researcher suggested that without any relevant treatment (outdoor education camp), perceptions toward group cohesion might remain unchanged overtime.

It was found that the control group recorded slightly increased (GI-T and GI-S) and decreased (ATG-T and ATG-S) but with no significant influences on social and task aspects. Researcher assumed that it is normal for the control group to record little improvement on their GI-T and GI-S score since they were in the third semester and exposed to social studies learning and Hubungan Etnik (Ethnic Relations) subject in their daily formal learning and informal practices. The researcher's claim regarding this issue was supported by several previous studies $[80,81,82]$. Other research suggests that individual characteristics may vary the relationships among group cohesion elements and participation. For example, in older adults 
it appears that ATG-S and ATG-T may be more likely to predict initial participation while GI-T and GI-S may be more likely to predict longer-term group membership [83]. Thus, this might be a possible reason for the increased and decreased of the control group scores after the camp. For that reason, it can be concluded that outdoor education camp interventions that used outdoor pursuit activities to increase group cohesion were more effective than simply having participants meet and attending class together [84].

However it is important to note that, central tendency effect might be involved in the research that used a pre-test and post-test research design where students might try to score low in pre-test and suppose to score higher during post-test [85]. Nevertheless the effect was found minimised in this study as both groups scored higher in the pre-test (according to GEQ scale, scored more than 20 out of 36 and 45 represents good level of group cohesion). In addition, the researcher never mentioned about post-test as subsequent to the pre-test to the participants. Therefore, by the end of the camp, the increase is not too drastic but incremental thus proposing that the central tendency issues has been minimised or may not exist at all.

On the other hand, the issue of gained score made by the experimental group might be argued as such improvement might not be the sole result of the outdoor education camp per se as pre-test might influence post-test result. Therefore, the researcher proposed that the issue was minimised by utilising MANCOVA analyses. MANCOVA is a multivariate test that minimised problem related to non-random by controlling the effect pre-test [86]. Based on the reason, the result generated by the analysis only highlighted the factual effect of the intervention.

\section{CONCLUSION}

In conclusion, this study details the effects of an outdoor education camp in short term and support the notion that outdoor education camp is effective in influencing the improvement of students' group cohesion. The whole findings of this study support the body of knowledge and practical aspect of Teacher Education Institute of Malaysia's outdoor education camps in enhancing positive group cohesion. The current study suggests that Teacher Education Institute of Malaysia's outdoor education camps are effective in improving students' group cohesion. In addition, the finding also revealed that GI-T and GI-S aspects scored higher than 
ATG-T and ATG-S aspects which can be translated that Teacher Education Institute of Malaysia's outdoor education camp promotes group outcomes more than individual outcomes. This finding also consistent with the findings by the other previous researchers such as Mazuki [31] and Boyle [26].

\section{ACKNOWLEDGEMENTS}

List here those individuals who provided help during the research (e.g., providing language help, writing assistance or proof reading the article, etc.).

\section{REFERENCES}

1. Williams, S.D., T.S. Graham, and B. Baker, Evaluating outdoor experiential training for leadership and team building. Journal of Management Development, 2003. 22(1).

2. American Institute for Research, Effect of outdoor education programs for children in California, A.I.f. Research, Editor 2005, American Institute for Research.

3. Shivers-Blackwell, S.L., Reactions to outdoor teambuilding initiatives in MBA education. Journal of Management Development, 2003. 23(7): p. 614-630.

4. Foley, J.M., Measuring student learning outcomes on Outward Bound courses and associated independent variables, in University of Colorado2009: Colorado.

5. Fiskum, T.A. and K. Jacobsen, Outdoor education gives fewer demands for action regulation and an increased variability of affordances. Journal of Adventure Education \& Outdoor Learning, 2012. 1(24).

6. Morgan, W. and M. Streb, Building citizenship: How student voice in service learning develops civic values. Social Science Quarterly, 2001. 82.

7. Ewert, A., P. Greg, and J. Sibthorp, Early-life outdoor experiences and an individual's environmental attitudes. Leisure Sciences, 2005. 27(1).

8. O'Bannon, P.M., The effect of the outdoor experiential rope course on perceived team performance, in Adult Education and Human Resources Development 2000, Florida International University: Miami, Florida.

9. Shivers-Blackwell, S.L., Reactions to outdoor teambuilding initiatives in MBA education. Journal of Management Development, 2004. 23(7): p. 614-630. 
10. Priest, S. and M. Gass, Effective leadership in adventure programming. Second ed2005, Champaign, IL: Human Kinetics.

11. Zink, R. and M. Boyes, The nature and scope of outdoor education in New Zealand schools. Australian Journal of Outdoor Education, 2006. 10(1): p. 11-12.

12. Brown, S., An exploration into outdoor education, 2007, University of Otago.

13. Soares, R.R., The impact of perceived risk from challenge courses on group cohesion in Postgraduate Graduate School2010, California Polytechnic State University: San Luis.

14. Kolb, D.A., Experiential learning: experience as the source of learning and development 1984: Prentice-Hall.

15. Rahimah, H.A., Educational development and reformation in Malaysia: Past, present and future. Journal of Educational Administration, 1998. 36(5): p. 462-475.

16. Ishak, R., Inilah kurikulum sekolah (This is school curriculum)2005, Kuala Lumpur: PTS Publisher.

17. Ministry of Education, Executive summary: Malaysia education blueprint 2013-2025 (Preschool to to post secondaryeducation), M.o. Education, Editor 2013, Ministry of Education: Putrajaya.

18. Ministry of Education. Falsafah pendidikan guru (Philosophy of teacher education). 2013;

Available

from:

http://web.moe.gov.my/ipgm/v2/index.php?option=com_content\&view=article\&id=98\&Itemi $\mathrm{d}=706 \&$ lang $=$ en.

19. Azita, A., Penilaian pelajar terhadap kompetensi pemimpin program pendidikan luar di institut pendidikan guru Malaysia (Student assessment on competency of leader in outdoor education programmes at Malaysia Teacher Education Institute), in Faculty of Educational Studies2007, Universiti Putra Malaysia: Serdang.

20. Ministry of Education, Proforma Pendidikan Luar (Outdoor education pro forma), 2001, Ministry of Education: Kuala Lumpur.

21. Aspenson, J.L., The influence of outdoor education to improve the quality of life for individuals with dementia thesis proposal, 2010, University of Minnesota: Duluth.

22. Eys, M.A., et al., Leadership status congruency and cohesion in outdoor expedition groups. The Journal of Experiential Education, 2008. 31(1): p. 78-94. 
23. Scholer, E.A. and T.L. Teoh, Teacher training in Physical Education in Malaysia. Journal of Physical Education and Recreation, 1980. 51(1): p. 74-77.

24. Bunting, C.J., Interdiciplinary teaching through outdoor education2006, Champaign: Human Kinetics.

25. McKenzie, M., How are adventure education program outcomes achieved?: A review of literature. Australian Journal of Outdoor Education, 2000. 5(1): p. 19-26.

26. Boyle, I.T., The impact of adventure-based training on team cohesion and psychological skill development in elite sporting team, in Faculty of Education2002, University of Wollonggng: Sydney.

27. Chang, A. and P. Bordia, A multi-dimensional approach to the group cohesion - group performance relationship. Small Group Research, 2006. 37(4).

28. Hatch, K.D. and C.J. McCarthy, Exploration of challenge courses' long-term effects on members of college student organizations. The Journal of Experiential Education, 2005. 27(3): p. $245-264$.

29. Garst, B.A., et al., Strengthening families: Exploring the impacts of family camp experiences on family functioning and parenting. The Journal of Experiential Education, 2013. 36(1): p. 65-77.

30. Stroud, S.M., The effects of team building activities on group climate and cohesion, in Faculty of The Graduate School2006, University of North Carolina: Greensboro.

31. Mazuki, M.Y., The impacts of outdoor education toward group cohesion and outdoor education attitudes in Faculty of Sport Science and Recreational2010, Universiti Teknologi MARA: Shah Alam.

32. Md Amin, M.T., et al., Residential outdoor education and environmental attitudes: an examination in a Malaysian University. Journal of Outdoor Recreation, Education, and Leadership, 2010. 2(3): p. 198-216.

33. Sibthorp, J., et al., Long-term impacts attributed to participant in adventure education: Preliminary finding from NOLS. Research in Outdoor Education, 2009. 9: p. 86-102.

34. Borland, J.F., L.J. Burton, and G.M. Kane, Sport Leadership in the 21st Century2014, Burlington, MA: Jones \& Bartlett Publishers

35. Knapp, D., The Thessaloniki Declaration: A Wake-Up Call for Environmental Education? 
The Journal of Environmental Education, 2000. 31(3): p. 32-39.

36. Bjorklund, D.F. and J.M. Bering, The evolved child - Applying evolutionary developmental psychology to modern schooling. Learning and Individual Differences, 2008. 12(4).

37. Tannenbaum, S., R. Beard, and E. Salas, Issues, theory and research in industrial/organizational psychology in Teambuilding and its influence on team effectiveness: An examination of conceptual and empirical developments, K. Kelley, Editor 1992, Elsevier: Amsterdam. p. 117-153.

38. Sheard, M. and J. Golby, The efficacy of outdoor adventure education curriculum on selected aspects of positive psychological development. Journal of Experiential Education, 2006. 29(2): p. 187-209.

39. Baumgartner, T.A. and L.D. Hensley, Conducting and reading research in health and performance. 4 ed. ISBN 007-125539-72006, New York: McGraw Hill.

40. Dror, I.E., Technology Enhanced Learning and Cognition2011, Amsterdam: John Benjamins Publishing.

41. Carron, A.V., L.R. Brawley, and W.N. Widmeyer, The Group Environmental Questionnaire: Test manual2002, West Virginia: West Virginia University.

42. Brawley, L.R., A.V. Carron, and W.N. Widmeyer, Assessing the cohesion of teams: Validity of the group environment questionnaire. Jouranl of Sport Psychology, 1987. 9(1): p. 275-294.

43. Cohen, J., Statistical power analysis for the behavioral sciences 2nd ed1988, Hillsdale, NJ: Erlbaum.

44. Miles, J. and M. Shevlin, Applying regression and correlation: A guide for students and researchers2001, London: Sage.

45. Çengelci், T., Social studies teachers' views on learning outside the classroom. Educational Sciences: Theory \& Practice, 2013. 13(3): p. 1836-1841.

46. Ross, E.W., The social studies curriculum: The purposes, problems and possibilities. 3rd ed2006, New York: State University of New York Press.

47. Amusa, L.O., A.L. Toriola, and T.D. Goon, Physical education and school sport in South Africa. The Global Journal of Health and Physical Education Pedagogy, 2013. 2(3): p. 
187-196.

48. Gurin, P., et al., Diversity and higher education: Theory and impact on educational outcomes. Harvard Educational Review, 2002. 72(3).

49. Place, G., Does interaction with the environment during the camping experience influence environmental attitudes?, 2004, Chicago State University: Chicago.

50. Lewis, T.G., Youth and nature: Assessing the impact of an integrated wellness curriculum on nature based play and nature appreciation for youth in out-of-school time recreation programming, in School of Graduate Studies2009, Universiti of Minnesota: Minnesota.

51. Thomas, G., Facilitator, teacher, or leader? Managing conflicting roles in outdoor education. The Journal of Experiential Education, 2010. 32(3): p. 239-254.

52. Kay, S., Effects of gender on small group cohesion: Mackenzie's Group Climate Questionnaire analyzed, 1996, Brigham Young University: Ann Arbor. p. 144-144 p.

53. McMillan, M., et al., Social and demographic influences on environmental attitudes. Southern Rural Sociology, 1997. 13(1).

54. Carron, A.V., et al., Do individual perceptions of group cohesion reflect shared beliefs?: An empirical analysis. Small Group Research, 2003. 34(4).

55. Hall, A., Sport psychology: Building group cohesion, performance, and trust in athletic teams G. Williamson, Editor 2007, Capella University Bullard, TX

56. Tazein, R. and Z. Meshkati, The effect of training the transactional analysis skills on athletes' group cohesion. Advances in Environmental Biology, 2014. 8(12): p. 1464-1467.

57. Whitaker, D., The spirit of teams. 1999, Marlborough, Wiltshire: The Crowood Press.

58. Warren, K., M. Sakofs, and J. Hunt, eds. Kurt Hahn and the aims of education. 3rd ed. The theory of experiential education, ed. T. James1995, Kendall/Hunt Publishing Co.

: Colorado.

59. Dion, K.L., Group cohesion: From "field of forces" to multidimensional construct. Group Dynamics: Theory, Research, and Practice, 2000. 4: p. 7-6.

60. Zaccaro, S.J., et al., Collective efficacy, in Self-efficacy, adaptation, and adjustment: Theory, research, and application, J.E. Maddux, Editor 1995, Plenum Press: New York. p. $305-328$.

61. Horn, T.S., Advances in sport psychology2008, Champaign, IL: Human Kinetics. 
62. Boone, K.S., P. Beitel, and J.S. Kuhlman, The effects of the win/loss record on cohesion. Journal of Sport Behavior, 1997. 20(2): p. 125-134.

63. Prapavessis, H. and A.V. Carron, Cohesion and work output. Small Group Research, 1997. 28(2): p. 294-301.

64. Carron, A.V., et al., Cohesion and performance in sport: A meta analysis. Journal Of Sport Exercise \& Psychology, 2002. 24: p. 168-188.

65. Meyer, B.B., The ropes and challenge course: a quasi-experimental examination. Perceptual and motor skills, 2000. 90(3 Pt 2): p. 1249-1257.

66. Carron, A.V., W.N. Widmeyer, and L.R. Brawley, The development of an instrument to assess cohesion in sport teams: The Group Environment Questionnaire. Journal of Sport Psychology, 1985. 7.

67. Yukelson, D., Principles of effective team building interventions in sport: A direct services approach at Penn State University. Journal of Applied Sport Psychology, 1997. 9(1): p. 73-96.

68. Malcarne, B.K., Exploring group cohesion in a higher education field experience, in Graduate School2012, Clemson University: Ann Arbor. p. 139.

69. Orndorff, J., The influence of treatment team cohesion in the success of in-home mental health treatment for children and adolescents with emotional and behavioral disorders, in Faculty of Antioch University2010, Antioch university: California.

70. Wilding, C., Improving quality of life after deinstitutionalisation through "ordinary adventure": A camping experience. Journal of Leisurability, 2000. 27(1).

71. Priest, S. and M. Gass, Effective leadership in adventure programming 1997, Champaign IL: Human Kinetics.

72. Milton, B. and E. Cleveland, Changing perceptions of nature, self, and others: A report on a park/school program. Journal of Environmental Education, 1995. 26(3): p. 32.

73. Glass, J.S. and K.P. Dotson-Blake, Adventure based counseling and school-based family counseling: Incorporating experiential education into the schools International Journal for School-Based Family Counseling 2010. 2.

74. Boyd-Franklin, N. and B.H. Bry, Reaching out in family therapy: Home-based, school and community interventions2000, New York, NY: Guilford Press. 
75. Breunig, M.C., et al. Psychological sense of community and group cohesion on wilderness trips. in The 35th Annual Association for Experiential Education's International Conference's 2007 2007. Little Rock, AK.: Symposium on Experiential Education Research.

76. Yuen, F.C., A. Pedlar, and R.C. Mannell, Building community and social capital through children's leisure in the context of an international camp. Journal of Leisure Research, 2005. 37(4): p. 494-518.

77. Breunig, M.C. and T.S. O'Connell, The impact of outdoor pursuits on college students' perceived sense of community. Journal of Leisure Research, 2010. 42(4): p. 551-572.

78. Jaffry, Z., The impact of National Service Program in Perlis state on group cohesion, in Faculty of Forestry2012, Universiti Putra Malaysia: Serdang.

79. Kolb, A.Y. and D.A. Kolb, Experiential learning theory: A dynamic holistic approach to management learning, education and development, in Handbook of management learning, education and development, S.J. Armstrong and C. Fukami, Editors. 2008, Sage Publications: London.

80. Saracho, O.N. and B. Spodek, Contemporary perspectives on social development in early childhood education. Vol. 3. 2007, Greenwich, Connecticut: Information Age Publishing.

81. Saracho, O.N. and B. Spodek, Handbook of research on the education of young children. Vol. 3. 2013, New York: Routledge: Taylor and Francis Group.

82. O'Brien, J., Are we preparing young people for 21 st -century citizenship with 20th-century thinking? A case for a virtual laboratory of democracy. Contemporary Issues in Technology and Teacher Education, 2008. 8(2).

83. Estabrooks, P.A. and A.V. Carron, The physical activity Group Environment Questionnaire: An instrument for the assessment of cohesion in exercise classes. Group Dynamics: Theory, Research, and Practice, 2000. 4(3): p. 230-243.

84. Burke, P., Contemporary social psychological theories.2006, Stanford, CA: Stanford University Press.

85. Baumgartner, T.A., C.H. Strong, and L.D. Hensley, Conducting and reading research in health and human performance 3rd ed2002, New York: McGraw-Hill.

86. Dimitrov, D.M. and P.D. Rumrill, Pretest-posttest designs and measurement of change. IOS Press, 2003. 20: p. 159-165. 


\section{How to cite this article:}

Yasim M. M., Aziz A., Md Taff M. A., and Zakaria J. Outdoor education camp and group cohesion: an investigation in the teacher education institute of Malaysia. J. Fundam. Appl. Sci., 2017, 9(6S), 1286-1311. 